PICTORIAL ESSAY

\title{
Primary hepatic lymphoma: Imaging findings
}

\author{
KM Elsayes, ${ }^{1}$ CO Menias,${ }^{2}$ JM Willatt, ${ }^{1}$ A Pandya ${ }^{1}$ and M Wiggins ${ }^{2}$ \\ ${ }^{1}$ Department of Radiology, University of Michigan Health System, Ann Arbor, Michigan and ${ }^{2}$ Mallinckrodt Institute of Radiology, Washington University, \\ St. Louis, Missouri, USA
}

KM Elsayes MD; CO Menias MD; J Willatt MD; A Pandya MD; M Wiggins MD.

\section{Correspondence \\ Assistant Professor Khaled M Elsayes, Department of Radiology, University of Michigan, 1500E. Medical Center Dr., Ann Arbor, MI 48109-5302, USA. \\ Email: kelsayes@med.umich.edu}

Conflict of interest: None.

Submitted 19 January 2009; accepted 19

March 2009

doi:10.1111/j.1440-1673.2009.02081.x

\begin{abstract}
Summary
Primary hepatic lymphoma (PHL) is rare, accounting for less than $1 \%$ of all extranodal lymphomas. In this article, we retrospectively reviewed the imaging features of 12 pathologically proven cases of primary hepatic lymphoma.
\end{abstract}

Key words: focal lesions; liver; lymphoma.

\section{Introduction}

Non-Hodgkin lymphoma is frequently seen in the liver as part of the spectrum of widespread disease. Primary hepatic lymphoma (PHL) is, however, rare, representing less than $1 \%$ of all extranodal lymphomas. ${ }^{1,2}$ Primary hepatic lymphoma presents with abdominal pain, fatigue, weight loss and a mass with or without jaundice. There is a male to female preponderance, ${ }^{2}$ and presentation is largely in middle age. The pathologic diagnosis is usually diffuse large cell lymphoma or large B-cell lymphoma, ${ }^{3,4}$ or immunoblastic lymphoma in immunosuppressed patients, in whom the incidence is increased. ${ }^{5}$

\section{Materials and methods}

We retrospectively reviewed the imaging findings of patients with a histological diagnosis of $\mathrm{PHL}$ between 1996 and 2001. The study population consisted of 12 patients (nine men and three women), with a mean age of 63 years. Presenting symptoms or signs included right upper quadrant pain (five), laboratory abnormalities (five), constitutional symptoms (two) and gastrointestinal symptoms (two). One patient was HIV positive.

Eight patients had CT examinations and 10 patients had ultrasound. Imaging characteristics and differential diagnostic considerations of PHL are presented.

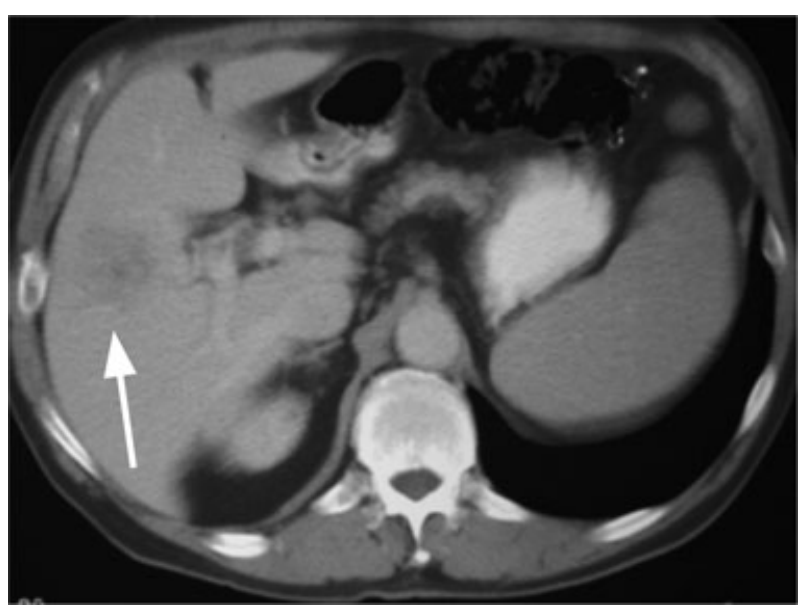

Fig. 1. Axial contrast enhanced CT shows a single $3 \times 4 \mathrm{~cm}$ heterogeneous hypoattenuating lesion (arrow) with areas of central necrosis.

\section{Results}

During the 5-year period, 12 patients who satisfied the criteria for $\mathrm{PHL}$, as described by Lei et al. ${ }^{3}$ underwent either ultrasound or CT examinations. Three of the 12 patients presented with a single focal lesion (Fig. 1). Eight of 12 patients presented with multiple well-defined lesions (Fig. 2). One patient presented with a diffuse hepatic involvement (Fig. 3). 

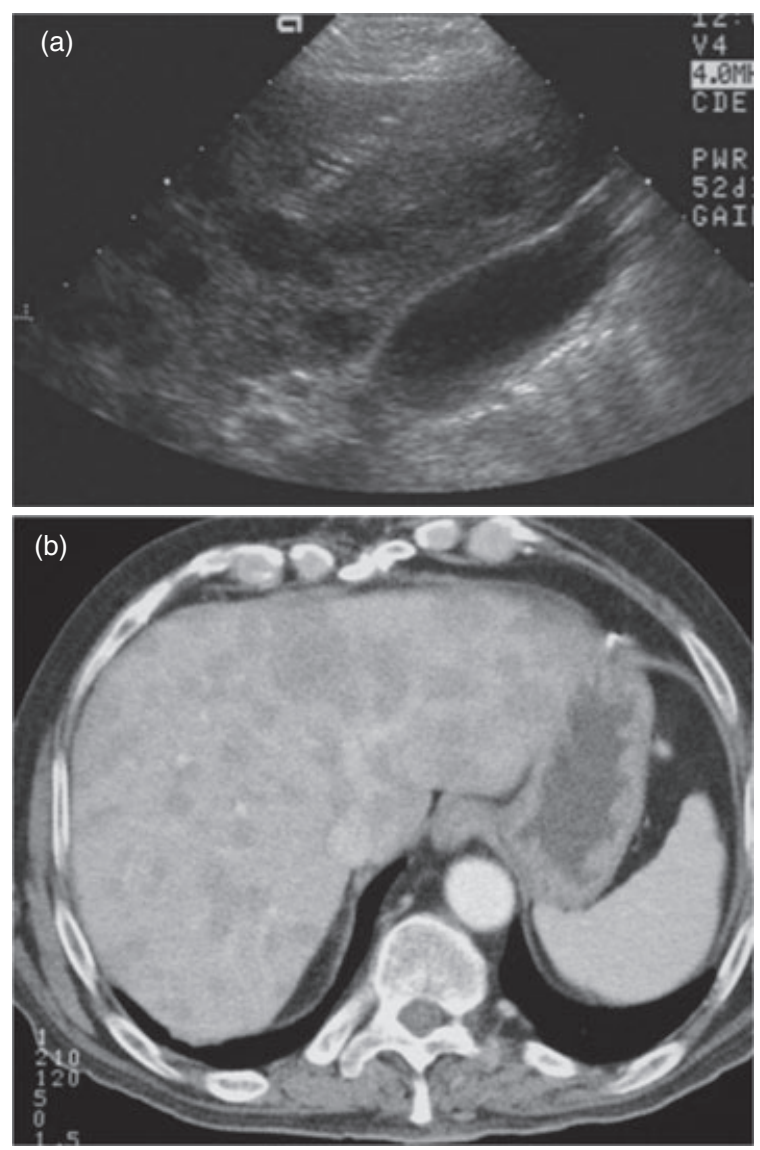

Fig. 2. (a) Ultrasound and (b) contrast enhanced axial CT images in a 67-yearold with abdominal pain show multiple well-defined hypoattenuating and hypoechoic lesions.

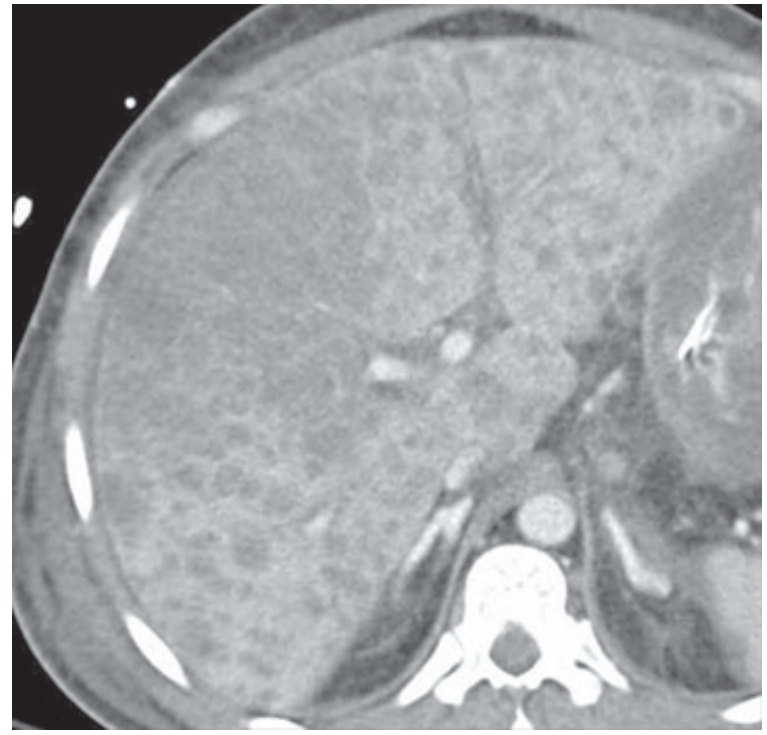

Fig. 3. Contrast-enhanced CT image shows diffuse heterogeneous ill-defined coalescent lesions in a 56-year-old woman with liver failure.

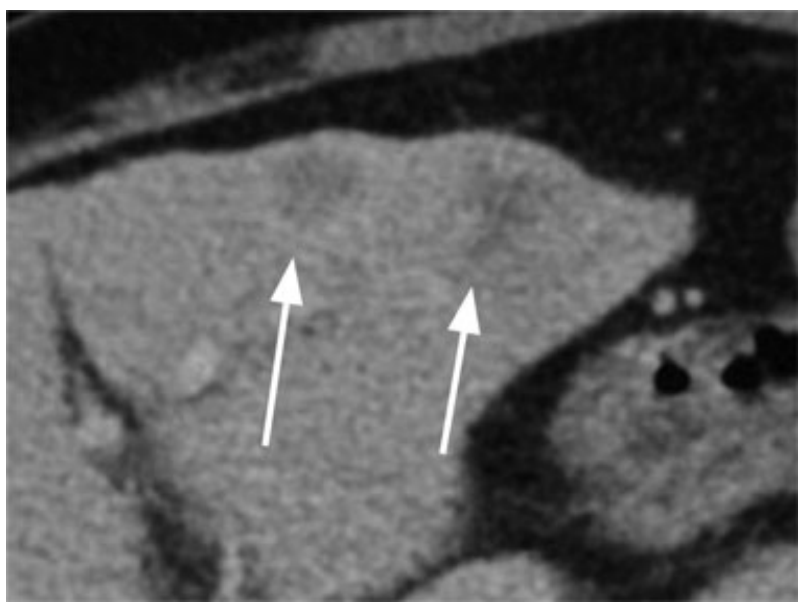

Fig. 4. Contrast enhanced CT shows two well defined lesions in the lateral segment of the left hepatic lobe (arrows)

All eight patients who underwent CT evaluation demonstrated hypoattenuating solid lesions. Most of these were well-defined lesions (Fig. 4). The lesions of three patients demonstrated rim enhancement following intravenous iodinated contrast administration (Fig. 5). Three patients demonstrated target lesions on $\mathrm{CT}$, with a hypoattenuating halo and central necrosis (Fig. 6).

All 10 patients who underwent ultrasound evaluation demonstrated solid appearing lesions, which were hypoechoic when compared with the adjacent liver (Fig. 7). In five patients, some or all of the lesions demonstrated a 'target' appearance on ultrasound imaging (Fig. 8). Fluorine-18-fluoro-2-deoxyglucose positron emission tomography (PET) was performed in one patient and demonstrated markedly increased uptake of the lymphomatous deposits (Fig. 9).

\section{Discussion}

Primary hepatic lymphoma represents a rare manifestation of the lymphoma spectrum. ${ }^{6,7}$ Presentation is

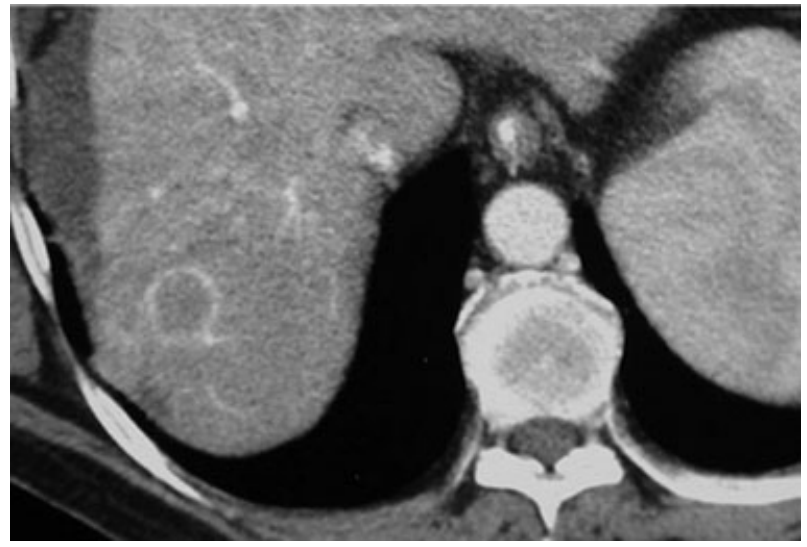

Fig. 5. Contrast enhanced CT shows a $1.9 \mathrm{~cm}$ well-defined ring enhancing lesion in the right hepatic lobe. 

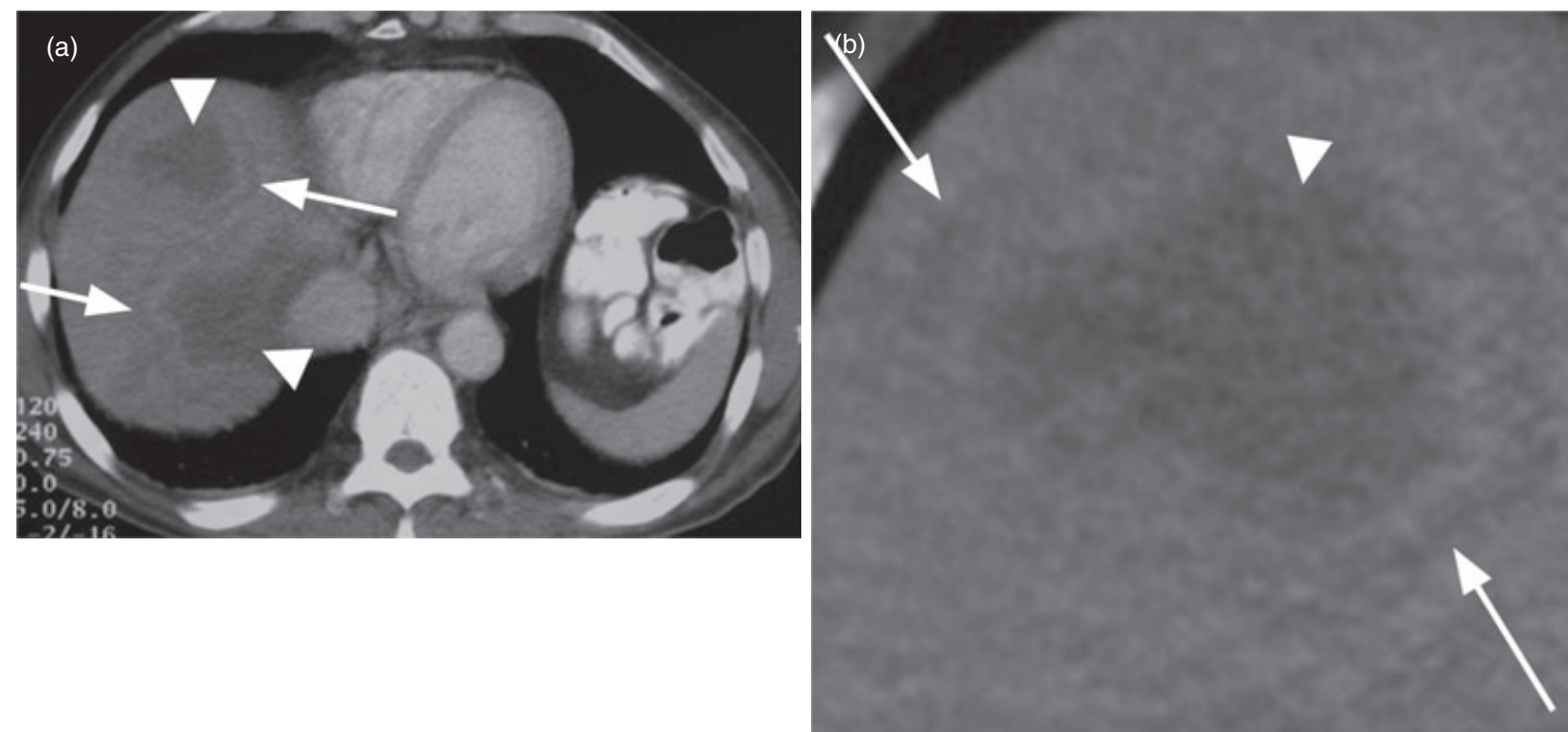

Fig. 6. (a,b) Contrast enhanced CT in a 58-year-old with $20 \mathrm{lb}$ weight loss shows lesions with hypoattenuating halos (arrows) surrounding enhancing intermediate zones. There is central hypoattenuating necrosis (arrowheads). The overall effect is of a target sign.
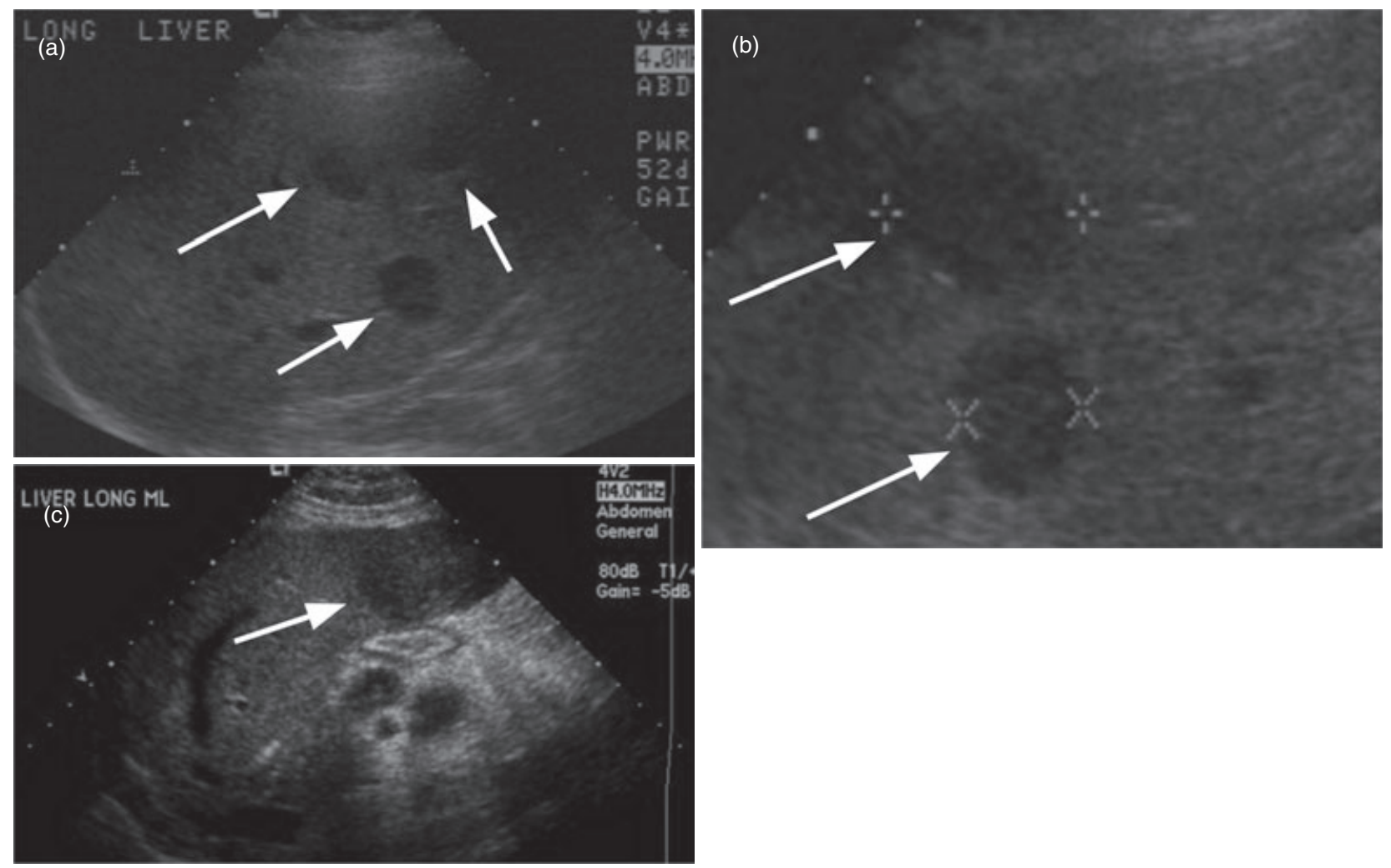

Fig. 7. (a-c) Ultrasound images in three different patients show well-defined hypoechoic lesions. 

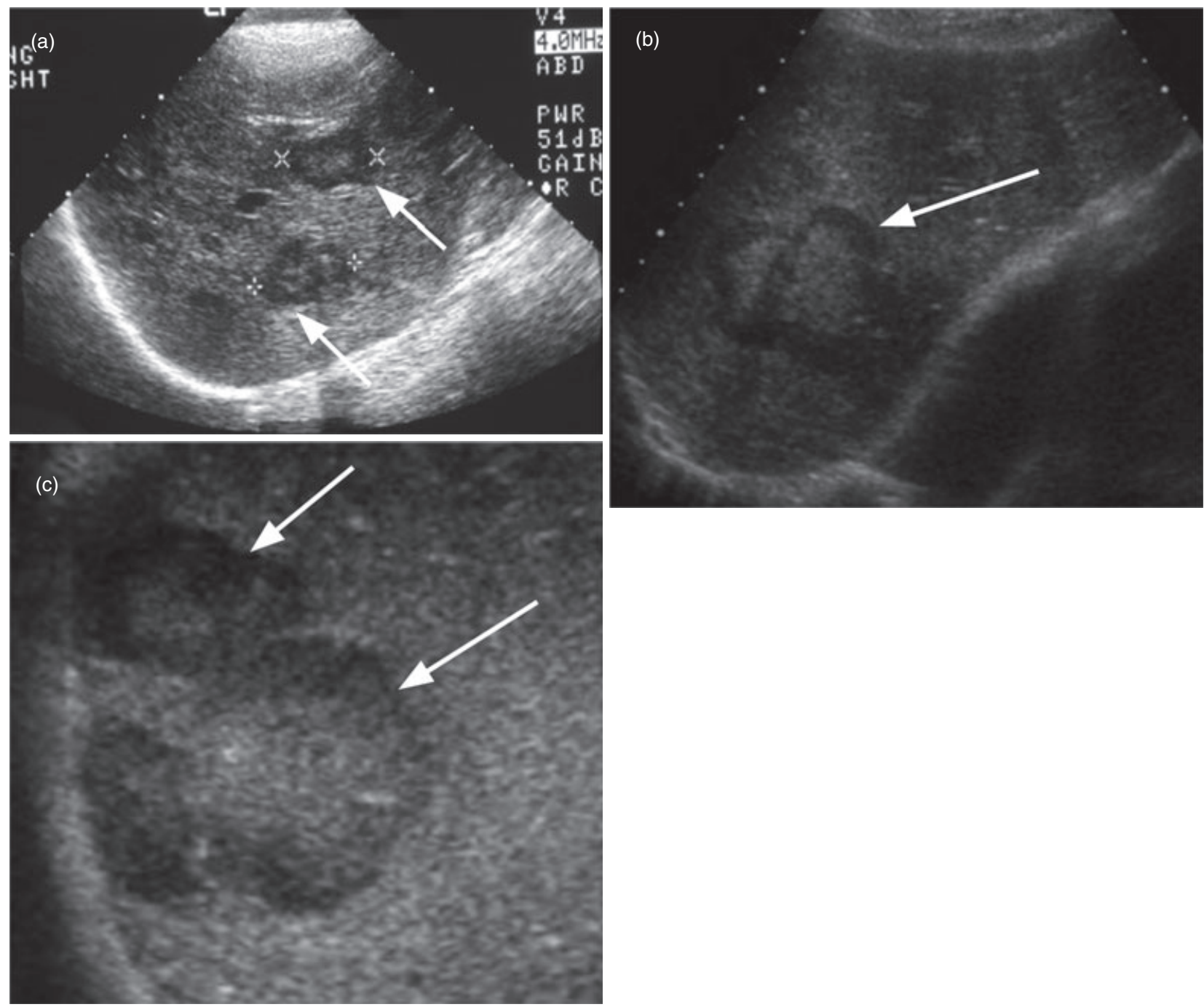

Fig. 8. Ultrasound images in three different patients show multiple lesions with hyperechoic centers and hypoechoic rims (arrows), creating a target appearance.

common during middle age, largely in the male population. ${ }^{8}$ Typical presenting complaints include right upper quadrant pain, nausea, vomiting and weight loss. ${ }^{2}$ Patients who present late often complain of a right upper quadrant mass or of hepatic fullness. Lactate dehydrogenase and alkaline phosphatase are sometimes elevated. ${ }^{4}$ Alpha-fetoprotein and carcinoembryonic antigen are often normal. ${ }^{4,9}$ Hypercalcaemia may also be present. ${ }^{9}$ Immunosuppression increases the risk of nonHodgkin's lymphoma. There is an association with infections with hepatitis C and hepatitis B viruses. ${ }^{10-12}$

The tumours are generally non-Hodgkin's in type. Diffuse large cell lymphoma is the most commonly encountered histological subtype. ${ }^{13}$ Almost invariably, the tumour is composed of lymphocytes reacting with B-cell markers. Most cases are intermediate or high grade according to the classification of the working formulation for clinical usage. AIDS-related non-Hodgkin's lymphomas are considered highly aggressive and can include small non-cleaved, large immunoblastic and undifferentiated cell types. ${ }^{5,14}$

Our results confirm previous reports that PHL can present as a solitary mass or as multiple discrete masses. ${ }^{15,16}$ Three of our eight patients demonstrated a single hepatic mass, and eight demonstrated multiple masses. Rarely, the disease presents as diffuse involvement of the liver. ${ }^{17}$ From our series of 12 patients, there was one case of diffuse disease. Our findings are concordant with previous papers describing the ultrasound appearances as of well-defined hypoechoic masses ${ }^{15,17}$ Our findings are also consistent with previous descriptions of hepatic lymphoma as of low attenuation on 

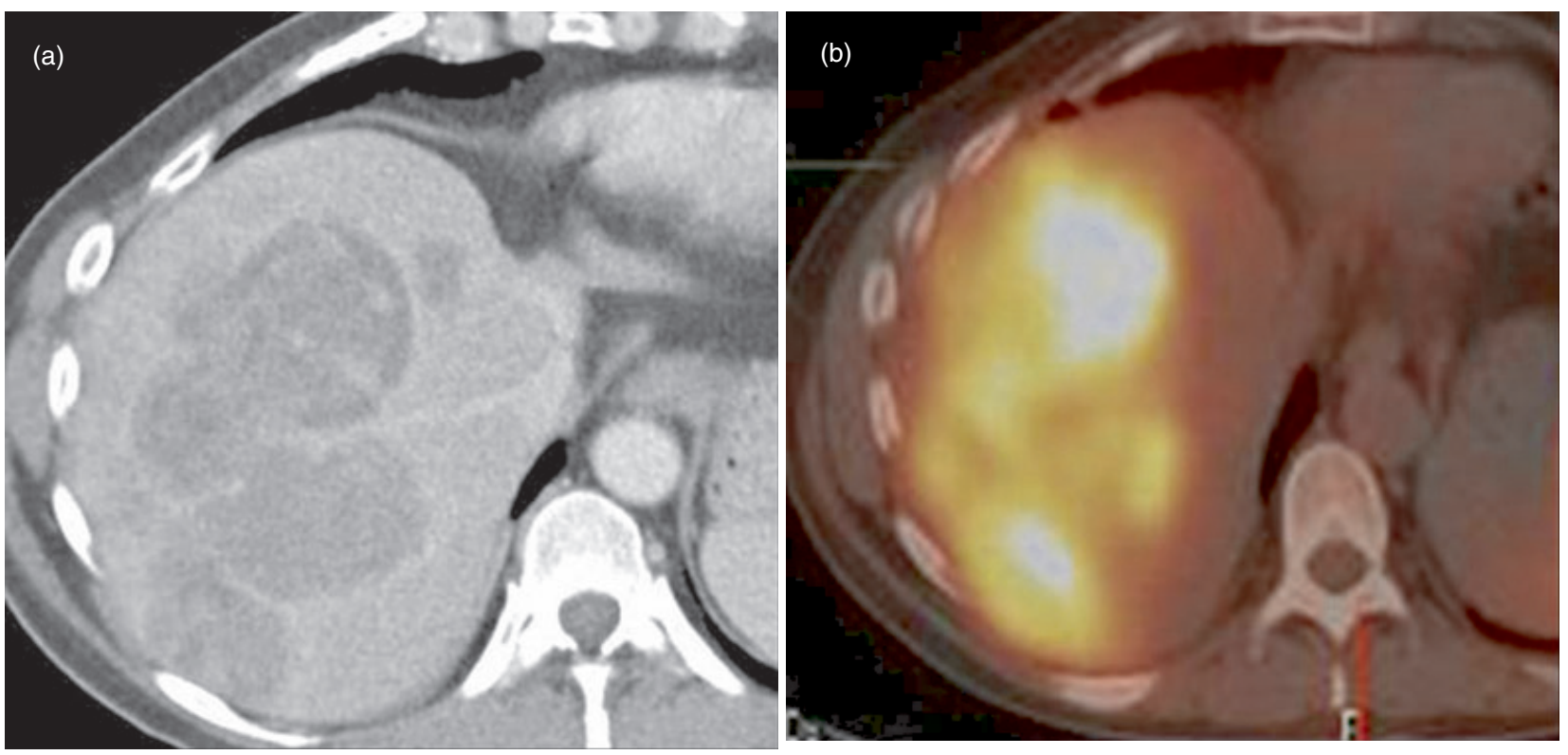

(c)

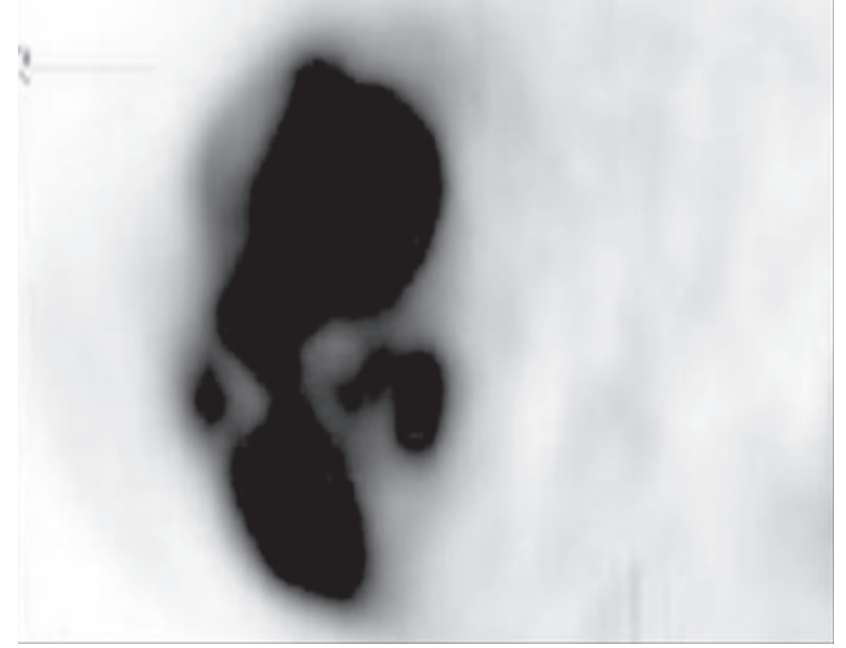

Fig. 9. 50-year-old male patient with primary hepatic lymphoma that showed (a) conglomerate low attenuation on contrast enhanced CT and (b,c) increased uptake on FDG PET.

CT. ${ }^{15,17,18}$ Rim enhancement has also been previously described. ${ }^{15}$ There was no calcification in our series. Calcification has been previously described. ${ }^{15,18}$ However, intravenous contrast was used in all of our cases, possibly resulting in obscuration of small foci of calcification. There are no previous reports, to our knowledge, describing the target appearances we identified in three of our eight patients at CT and in five of our 10 patients at ultrasound.

The criteria for establishing the diagnosis of $\mathrm{PHL}$ include both clinical and histopathological factors. In addition to histological evidence of hepatic Iymphoma, Lei et al. ${ }^{3}$ described the following criteria to establish the diagnosis:

1 Signs and symptoms related to liver involvement at presentation including laboratory abnormalities and right upper quadrant mass or pain

2 Absence at presentation of palpable adenopathy and no radiologically evident distant lymphadenopathy

3 Absence of leukaemia on peripheral smear

Fluorine-18-fluoro-2-deoxyglucose PET is frequently utilised with lymphoma. The majority of Iymphomatous 
deposits should demonstrate increased uptake, and the level of uptake may correlate with disease activity and tumour proliferation. ${ }^{19}$ This is concordant with the finding of increased uptake when PET was studied in a single case of our series.

The imaging appearance of hepatic lymphoma is nonspecific and mainly includes hypovascular metastatic deposits. Colon, lung, prostate, gastric and transitional cell carcinomas are the most common primary tumours with hypovascular metastases to the liver. ${ }^{20}$ Infectious (such as fungal and microbacterial) and inflammatory (such as sarcoidosis) pathologies can sometimes result in similar imaging appearances with multiple focal hepatic lesions, but clinical and laboratory values can often help in their differentiation.

There is little consistency in the literature regarding treatment of PHL. ${ }^{21}$ The prognosis is generally perceived as dismal, with early disease recurrence at extra-hepatic locations and an overall short survival. ${ }^{3}$ Reported median survival is as low as 6 months for patients treated with chemotherapy alone. Surgery and combination chemotherapy, either alone or with radiation, have all been described as viable management options. While there is little consistency in recommendations for management, recent studies indicate improved remission rates with combination chemotherapy. ${ }^{4}$ High risk factors at the time of diagnosis include patient age, bulky disease and comorbidities, such as active hepatitis or cirrhosis. Given these factors, early detection is vital for patient management.

\section{Conclusion}

Primary hepatic lymphoma is a rare form of extranodal non-Hodgkin's disease that commonly presents with non-specific haepatobiliary signs and symptoms. There is a wide spectrum of imaging findings on CT and ultrasound. Like many other hepatic malignancies, PHL generally presents as hypoattenuating or hypoechoic lesions. Lesions may be single, multiple or diffuse. Rim enhancement is occasionally seen. A target appearance to the lesions on both ultrasound and CT is also seen. Primary hepatic lymphoma should be considered in the differential diagnosis of liver lesions when no primary malignancy is known.

\section{References}

1. Harris AC, Ben-Ezra JM, Contos MJ, Kornstein MJ. Malignant lymphoma can present as hepatobiliary disease. Cancer 1996; 78: 2011-19.

2. Lei KI. Primary non-Hodgkin's lymphoma of the liver. Leuk Lymphoma 1998; 29: 293-9.

3. Lei KI, Chow JH, Johnson PJ. Aggressive primary hepatic lymphoma in Chinese patients. Presentation, pathologic features, and outcome. Cancer 1995; 76: 1336-43.

4. Page RD, Romaguera JE, Osborne B et al. Primary hepatic lymphoma: favorable outcome after combination chemotherapy. Cancer 2001; 92: 2023-29.

5. Rizzi EB, Schinina V, Cristofaro M, David V, Bibbolino C. Non-Hodgkin's lymphoma of the liver in patients with AIDS: sonographic, CT, and MRI findings. J Clin Ultrasound 2001; 29: 125-9.

6. Aozasa K, Mishima K, Ohsawa M. Primary malignant lymphoma of the liver. Leuk Lymphoma 1993; 10: 353-7.

7. Schweiger F, Shinder R, Rubin S. Primary lymphoma of the liver: a case report and review. Can J Gastroenterol 2000; 14: 955-7.

8. Ozet A, Caliskaner Z, Deveci S et al. Primary non-Hodgkin's lymphoma of the liver (case report). Tumori 2000; 86: 492-4.

9. Seymour JF, Gagel RF, Hagemeister FB, Dimopoulos MA, Cabanillas F. Calcitriol production in hypercalcemic and normocalcemic patients with non-Hodgkin lymphoma. Ann Intern Med 1994; 121: 633-40.

10. Genvresse I, Spath-Schwalbe E, Meisel H, Kaufmann $\mathrm{O}$, Kruger DH, Possinger K. Primary hepatic or splenic diffuse large B-cell lymphoma and hepatitis C virus infection: a non-fortuitous association? Ann Hematol 2000; 79: 530-32.

11. Matano S, Nakamura S, Annen Y et al. Primary hepatic lymphoma in a patient with chronic hepatitis B. Am J Gastroenterol 1998; 93: 2301-2.

12. Chen HW, Sheu JC, Lin WC, Tsang YM, Liu KL. Primary liver lymphoma in a patient with chronic hepatitis C. J Formos Med Assoc 2006; 105: 242-6.

13. Memeo L, Pecorello I, Ciardi A, Aiello E, De Quarto A, Di Tondo U. Primary non-Hodgkin's lymphoma of the liver. Acta Oncol 1999; 38: 655-8.

14. Villafane MF, Trione N, Corti M et al. Primary liver AIDS-related lympoma. Rev Inst Med Trop Sao Paulo 2006; 48: 229-31.

15. Maher MM, McDermott SR, Fenlon HM et al. Imaging of primary non-Hodgkin's lymphoma of the liver. Clin Radiol 2001; 56: 295-301.

16. Kelekis NL, Semelka RC, Siegelman ES et al. Focal hepatic lymphoma: magnetic resonance demonstration using current techniques including gadolinium enhancement. Magn Reson Imaging 1997; 15: 625-36.

17. Gazelle GS, Lee MJ, Hahn PF, Goldberg MA, Rafaat N, Mueller PR. US, CT, and MRI of primary and secondary liver lymphoma. J Comput Assist Tomogr 1994; 18: 412-5.

18. Sanders LM, Botet JF, Straus DJ, Ryan J, Filippa DA, Newhouse JH. CT of primary lymphoma of the liver. AJR Am J Roentgenol 1989; 152: 973-6.

19. Goldberg MA, Lee MJ, Fischman AJ. Fluorodeoxyglucose PET of abdominal and pelvic 
neoplasms: potential role in oncologic imaging. Radiographics 1993;13: 1047-62.

20. Elsayes KM, Narra VR, Yin Y et al. Focal hepatic lesions: diagnostic value of enhancement pattern approach with contrast-enhanced 3D gradient-echo MR imaging. RadioGraphics 2005; 25 (5): 1299-320.

21. Levy AD. Malignant liver tumors. Clin Liver Dis 2002; 6: $147-64$. 